\title{
Central venous pressure monitoring and mortality: What was neglected?
}

Shaowei Gao, Zhanxin Du, Lu Yang and Zhongxing Wang*

Dear editor,

We are interested in the recent published article about the association between central venous pressure (CVP) monitoring and mortality for ICU patients with sepsis [1]. The study provides new insights into this traditional monitoring. However, an important factor might make the study more convincing if it had been taken into account.

The clinical experience tells us that ICU admissions after surgeries (surgical patients in the ICU) are more likely to have central venous catheters than those from the medical system (medical patients in the ICU). Besides, as has been proven by many studies, medical patients have worse prognosis than surgical patients in the ICU [2-4]. Chen and his colleagues collected tens of important covariates to adjust the results, but the admission resource (from surgical or medical systems, which can be identified with the official codes [5]) was neglected [1]. To validate our supposition, we conducted an analysis in the same database. According to the inclusion and exclusion criteria of Chen's study, we extracted a very similar $(10,131)$ but not identical $(10,275)$ cohort (because we didn't get the authors' original codes). The CVP monitoring group has 4,505 patients (vs. 4516 in Chen's study), while the non-CVP monitoring group has 5626 ones (vs. 5759 in Chen's study). As shown in the mosaic plot (Fig. 1a), CVP monitoring is positively associated with ICU admissions after surgery (1574/4505 [35\%] for CVP group vs 835/5626 [15\%] for non-CVP group, Phi coefficient $=0.235, \mathrm{p}<0.001)$. And the 28-day mortality is significantly lower among surgical patients

*Correspondence: wzhxing@mail.sysu.edu.cn

Department of Anesthesia, The First Affiliated Hospital of Sun Yat-Sen

University, 58 Zhongshan 2nd Road, Guangzhou 510080, China
(12\% for surgical patients vs $21 \%$ for medical patients, relative risk [95\% confidence interval]: 0.60 [0.53-0.67], $\mathrm{p}<0.001)$. Briefly, the CVP monitoring group has a larger proportion (more than twice the non-CVP monitoring group) of surgical patients, which has a lower 28-day mortality rate (nearly a half) than medical patients. Not considering the admission resources may bring bias to Chen's study.

Service units of patients in the MIMIC database (MICU, SICU/TSICU and CCU/CSRU in Chen's study) were collected as a covariate. Except for MICU, the other two units were balanced in the numbers of surgical and medical patients (Fig. 1b). As a result, the proportions of surgical and medical patients could not be adjusted between CVP monitoring and non-CVP monitoring groups, which means that the effect of admission resources could not be replaced by service units. We would be very interested in the results if the effect of admission resources were considered.

\section{Acknowledgements \\ We appreciate the researchers at the MIT Laboratory for Computational Physi- ology for publicly sharing of the MIMIC-III database.}

\section{Authors' contributions}

ZW conceived the idea and takes responsibility for the content of the manuscript. SG did the major work of data extraction and analysis. The authors meet the criteria for authorship as recommended by the International Committee of Medical Journal Editors (ICMJE). Writing and edition were provided by SG, ZD, $L Y$ and ZW. All authors read and approved the final manuscript.

\section{Funding}

The authors received no funding for this study.

\section{Availability of data and materials}

The datasets extracted and analyzed during the current study are accessed in this website (https://mimic.physionet.org/gettingstarted/access/).

Ethics approval and consent to participate Not applicable.

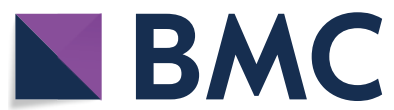

(c) The Author(s) 2020. Open Access This article is licensed under a Creative Commons Attribution 4.0 International License, which permits use, sharing, adaptation, distribution and reproduction in any medium or format, as long as you give appropriate credit to the original author(s) and the source, provide a link to the Creative Commons licence, and indicate if changes were made. The images or other third party material in this article are included in the article's Creative Commons licence, unless indicated otherwise in a credit line to the material. If material is not included in the article's Creative Commons licence and your intended use is not permitted by statutory regulation or exceeds the permitted use, you will need to obtain permission directly from the copyright holder. To view a copy of this licence, visit http://creativecommons.org/licenses/by/4.0/. The Creative Commons Public Domain Dedication waiver (http://creativeco mmons.org/publicdomain/zero/1.0/) applies to the data made available in this article, unless otherwise stated in a credit line to the data. 

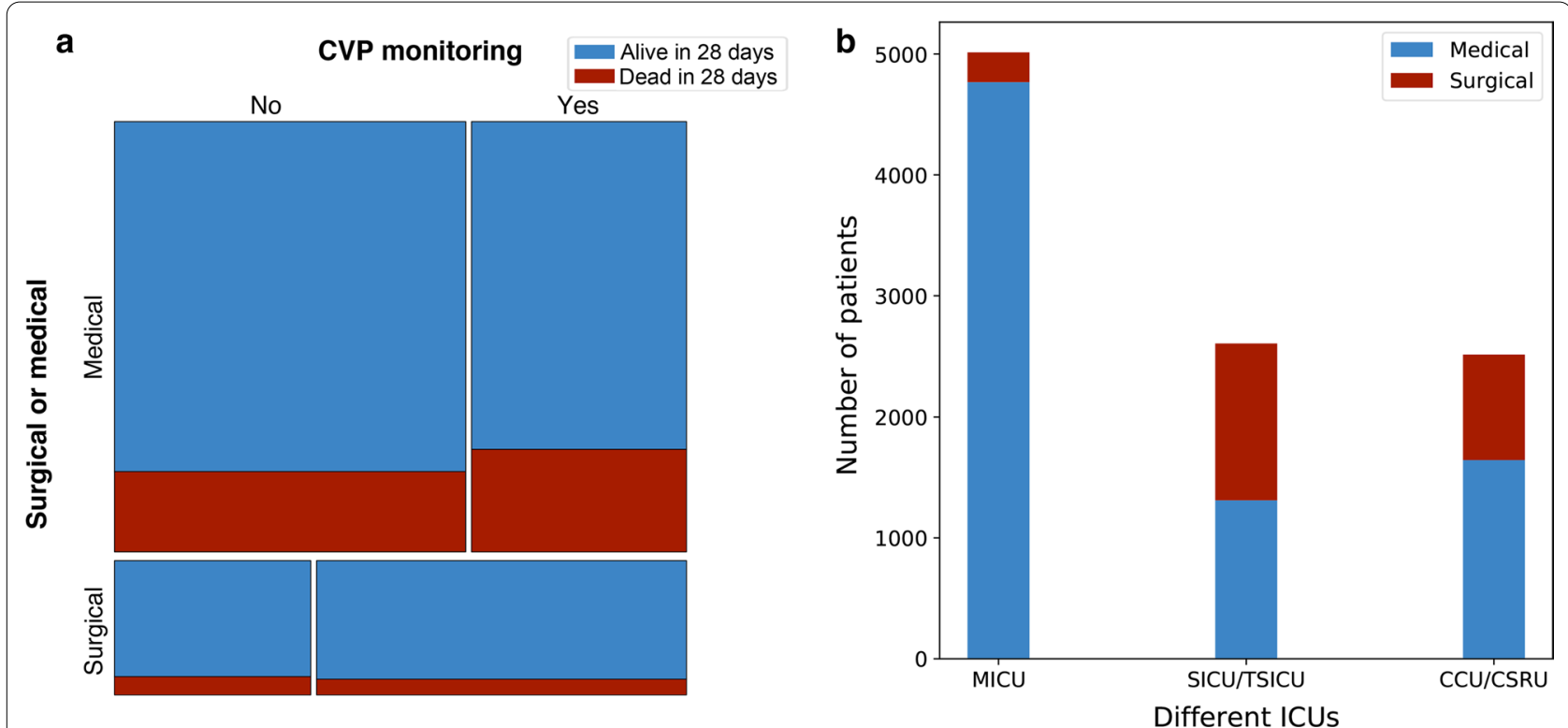

Fig. 1 a The mosaic plot for the association of CVP monitoring and Admission resources (from surgical or medical systems). The area of each block refers to the number of patients for each category. These categories are marked horizontally by CVP monitoring and vertically by Admission resources. The red portion of each block refers to 28-day mortality. $\mathbf{b}$ The bar chart of numbers of patients in different ICUs. The numbers of all, surgical and medical patients can be identified for each kind of ICUs. CVP central venous pressure, ICU intensive care unit, MICU medical intensive care unit, SICU surgical intensive care unit, TSICU trauma surgical intensive care unit, CCU coronary care unit, CSRU cardiac surgery unit

\section{Consent for publication}

Not applicable.

\section{Competing interests}

The authors declare that they have no conflict of interest.

Received: 24 September 2020 Accepted: 16 October 2020

Published online: 23 October 2020

\section{References}

1. Chen H, Zhu Z, Zhao C, Guo Y, Chen D, Wei Y, Jin J. Central venous pressure measurement is associated with improved outcomes in septic patients: an analysis of the MIMIC-III database. Crit Care. 2020;24(1):433.

2. De Jong A, Verzilli D, Sebbane M, Monnin M, Belafia F, Cisse M, Conseil M, Carr J, Jung B, Chanques G, et al. Medical versus surgical ICU obese patient outcome: a propensity-matched analysis to resolve clinical trial controversies. Crit Care Med. 2018;46(4):e294-301.

3. Le Gall JR, Lemeshow S, Saulnier F. A new Simplified Acute Physiology Score (SAPS II) based on a European/North American multicenter study. JAMA. 1993;270(24):2957-63.

4. Puxty K, McLoone P, Quasim T, Kinsella J, Morrison D. Survival in solid cancer patients following intensive care unit admission. Intensive Care Med. 2014:40(10):1409-28.

5. mimic-code/concepts/severityscores/sapsii.sql. https://github.com/ MIT-LCP/mimic-code/blob/master/concepts/severityscores/sapsii.sql. Accessed 20 Sept 2020

\section{Publisher's Note}

Springer Nature remains neutral with regard to jurisdictional claims in published maps and institutional affiliations.
Ready to submit your research? Choose BMC and benefit from:

- fast, convenient online submission

- thorough peer review by experienced researchers in your field

- rapid publication on acceptance

- support for research data, including large and complex data types

- gold Open Access which fosters wider collaboration and increased citations

- maximum visibility for your research: over $100 \mathrm{M}$ website views per year

At BMC, research is always in progress.

Learn more biomedcentral.com/submissions 